\title{
Differential contribution of soil biota groups to plant litter decomposition as mediated by soil use
}

Ricardo A Castro-Huerta, Liliana B Falco, Rosana V Sandler, Carlos Coviella

Plant decomposition is dependant on the activity of the soil biota and its interactions with climate, soil properties, and plant residue inputs. This work assessed the roles of different groups of the soil biota on litter decomposition, and the way they are modulated by soil use. Litterbags of different mesh sizes for the selective exclusion of soil fauna by size (macro, meso, and microfauna) were filled with standardized dried leaves and placed on the same soil under different use intensities: Naturalized grasslands, recent agriculture, and intensive agriculture fields. During five months, litterbags of each mesh size were collected once a month per system with five replicates. The remaining mass was measured and decomposition rates calculated. Differences were found for the different biota groups, and they were dependant on soil use. Within systems, the results show that in the naturalized grasslands, the macrofauna had the highest contribution to decomposition. In the recent agricultural system it was the combined activity of the macro and mesofauna, and in the intensive agricultural use it was the mesofauna activity. These results underscore the relative importance and activity of the different groups of the edaphic biota and the effects of different soil uses on soil biota activity. 
$9 \quad{ }^{1}$ Ecology Laboratory, Terrestrial Ecology Research Program, Basic Sciences Department - Ecology

10 and Sustainable Development Institute, National University of Luján. Av. Constitución y Ruta 5

11 (6700). Luján, Buenos Aires, Argentina.

12

13

14 Corresponding author:

15 Eng. Ricardo A. Castro-Huerta

16 Ecology Laboratory, Terrestrial Ecology Research Program, Basic Sciences Department -National 17 University of Luján.

18 Av. Constitución y Ruta 5 (6700). Luján, Buenos Aires, Argentina.

$19+54-2323-420380$ \#249

20 Mail: ricardoach@yahoo.com 
21 1. Introduction

The edaphic biota is the main factor directly responsible for soil organic matter turnover and

23 nutrient cycling due to the diversity of processes in which it takes part (Lavelle and Spain, 2001;

24 Lavelle et al., 2006; Brussaard et al., 2007; Culliney, 2013). Among these, the fragmentation and

25 incorporation of plant residues into the soil; the construction and maintenance of the structural porosity

26 and soil aggregation, are some of the processes the edaphic biota is involved with that have effects on

27 other organisms (Lavelle et al., 2006; Culliney, 2013). This way, multiple interactions with other

28 organisms are developed, on different scales and through the entire range of chemical, physical, and

29 biological processes that support the ecosystem services provided by the soil (Brussaard et al., 2007;

30 Culliney, 2013). Lavelle et al. (1993) found that the activity of macroorganisms is particularly

31 important in the regulation of the decomposition process. In particular, these authors state that

32 interactions between macro and microorganisms are very intense in areas where climate is more or less

33 constant. In turn, this biological interaction is associated with the energy source, fungi and bacteria

34 communities, and macroorganisms which create conditions suitable for optimal microbial activity.

35 When environmental traits like the climate are not limiting (drought or flooding) and clay minerals are

36 not very reactive (or do not make a significant contact with the biota), the biological regulation systems

37 take a predominant role in the decomposition of leaf litter (Lavelle et al., 1993; Gonzalez and Seastedt,

38 2001; Dechaine et al., 2005).

39 Soil fauna largely control the decomposition process through breakdown of litter. digestion, and

40 stimulation of microorganism activities (Yang and Chen,2009). Their study indicated that soil fauna

41 assemblage provided a significant contribution to litter decomposition in all three sites of their study

42 (rainforest, broad-leaf forest and secondary forest), while the contribution of soil fauna to plant litter

43 decomposition was more pronounced in the rainforest than the other two sites. Fauna effects increased

$44 \mathrm{~N}$ concentration and decreased $\mathrm{C}$ concentration in litter with high initial $\mathrm{C} / \mathrm{N}$ ratio, which may explain 
45 the significant fauna effect on litter decomposition in the rain forest. A similar observation regarding

46 the relation $\mathrm{C} / \mathrm{N}$ was presented by $\mathrm{Li}$ et al (2014).

The edaphic biota is classified according to the size of the adults into three groups: the microfauna, the mesofauna, and the macrofauna (Lavelle and Spain, 2001; Eisenbeis, 2006; Lavelle et al., 2006). Each component fulfills a specific role in its specific ecological niche that is hard to replace with other components present in the system (Lavelle et al., 2006) taking part in different processes

51 affecting soil fertility in at least two main ways. Firstly, by promoting decomposition directly through 52 the conversion of plant litter into their own tissues, and indirectly transforming the plant litter 53 physically and chemically into substances amenable to further degradation by microflora. Secondly, by 54 their effects on the physical structure of the soil (Culliney, 2013) that may be affected by agricultural 55 soil use (Baker, 1998; Bardgett and Cook, 1998) Agroecosystems are continuously under the anthropic impact of different agricultural practices, which causes changes in their biotic and abiotic components both in time and in space. These changes

58 in turn, affect the structure and function of the soil biota (Dominguez et al. 2014, Liiri et al., 2012), 59 thus mediating the biological processes in the soil, which affects the flow of matter and energy in the 60 entire system (Lubchenko et al., 1991). Ponge et al.(2013) show that soil animals (except epigeal 61 springtails) and microbial community are adversely affected by the increase in agricultural 62 intensification. The soil fauna responds to the agricultural management as a result of the physico63 chemical disturbances that are produced in its habitat, of the distribution of the residues, and of the 64 plant communities present (Lavelle and Spain, 2001; Kautz et al., 2006). In order to understand in greater detail the role of the different soil fauna groups in the 66 decomposition process, the hierarchical model proposed by Lavelle et al. (1993) was followed. To 67 isolate the effects of different agricultural management practices, fields with the same soil and climate 68 in three levels of agricultural use intensity were selected, and factors such as resource quality were 
76 intensities. evaluated.

standardized. To assess the different contributions of the soil fauna in the decomposition process the technique of the litterbags (Crossley and Hoglund, 1962) was used.

Three litterbag mesh sizes were used to hierarchically exclude each group of the edaphic biota according to size. Therefore, the contribution of each group to organic matter decomposition was

The working hypothesis was that plant litter decomposition rates would differ between the different soil fauna groups, and that those differences would be modulated by the different soil use

\section{Materials and Methods}

The study was carried out in the rolling pampas of central Argentina. With over fifty million hectares of agricultural land, it is one of the biggest and most productive plains in the world (Navarrete et al,, 2007; Faggi et al., 2008). Three agroecosystem types with different intensities of soil use were selected as treatments. The agroecosystems were located near Chivilcoy city in the Buenos Aires province, Argentina $\left(35^{\circ} 03^{\prime} 00^{\prime \prime} \mathrm{S} ; 59^{\circ} 41^{\prime} 00^{\prime \prime} \mathrm{W}\right)$ (Fig. 1).

The soil for all treatments was a mollisol from the typical arguidoll group (USDA, 2010). In increasing order of soil use intensity, the selected agroecosystems were: 1- Naturalized grasslands with no anthropic impact in almost 50 years $(\mathrm{NG})$. Natural litter in this agroecosystem was typically from naturally occurring grasses dominated by Festuca sp., 2- Cattle-grazing fields turned into agriculture 2 years before the start of the study (RA). Litter in this place was dominated by agricultural species, such as soybean and corn in summer and wheat in winter, and 3- Intensive Agriculture fields with almost 40 years of continuous and intensive agriculture (IA). Litter in this place was dominated by soybean. All the fields were left fallow during the duration of this experiment. The experimental sites ranged in size from 0.5 to 45 hectares.

Five different sites per treatment (soil use intensity) were selected as replicates. At each site, 
93 decomposition bags $(20 \times 20 \mathrm{~cm})$ were placed with three different mesh sizes for the selective

94 exclusion of the epigeic soil organisms according to size: $4 \mathrm{~mm}$ mesh size (Microfauna + Mesofauna +

95 Macrofauna, hereafter Total Biota); $2 \mathrm{~mm}$ mesh size for the selective exclusion of the Macrofauna

96 (Microfauna + Mesofauna); and $0.25 \mathrm{~mm}$ mesh size to further exclude the Mesofauna (hereafter

97 Microfauna). These different size-excluded groups represent three different complexity groups of the 98 soil biota.

In each bag $5 \mathrm{~g}$ of dry, senescent soybean leaves (Glycine max L.) were placed. Soybean leaves

100 were used to standardize the litter material offered, because it was the last crop in the agricultural 101 systems, and it has been the most common crop in the region during the last ten years. The senescent

102 leaves were collected in the same field on autumn before harvest and dried at $30{ }^{\circ} \mathrm{C}$. The bags were

103 placed on the surface of the soil and covered lightly with plant residues after harvest to improve the

104 natural decomposition of this crop in the pampas on end-autumn, winter and spring. A total of 270

105 litterbags were distributed among treatments and replicates, with no more than 10 bags per square

106 meter at any site The experiment was set to run for six sampling dates, but it was terminated after five

107 months when one of the replicates approached zero RM. Bags were retrieved at 17, 53, 94, 126, and

108171 days after the bags were placed. Every sampling date, one bag of each mesh size (3) was retrieved

109 per replicate (5) and agroecosystem (3), thus processing 45 litterbags each sampling date, for a total of

110225 litterbags over the 5 sampling dates. The material was then dried at $30^{\circ} \mathrm{C}$ to constant weight. The

111 remaining material was weighted and the percentage of remaining mass (\%RM) calculated.

112 With these data, we performed a two-way ANOVA for discriminate the effects of both factors

113 mesh-size and agricultural use, in case of found any difference, the decomposition rate for each case

114 was calculated, assuming a negative exponential model following Olsen (1963):

$$
R M=I M * e^{-k t}
$$


Where:

$$
\begin{aligned}
& \text { RM= Remaining Mass } \\
& \text { IM = Initial Mass } \\
& \mathrm{t}=\text { Time (Days) } \\
& \mathrm{k}=\text { Decomposition rate }
\end{aligned}
$$

This exponential model was linearized using the natural logarithm of the remaining mass $122(\% \mathrm{RM})$ and the transformed data were analyzed with ANCOVA to compare the slopes of each case 123 with the Tukey test (HSD) between different cases with a 95\% confidence interval.

125 computing (2010).

126 3. Results

The results of percentage remaining mass $(\% \mathrm{RM})$ found for each edaphic biota group within agricultural systems analyzed by two-way ANOVA can be seen on table 1. Statistical differences were

129 found for the mesh size factor. No differences were found for agricultural use alone, or the interaction 130 between main factors.

131 These results allow for the analysis of the slopes of the decomposition rates between different 132 mesh sizes within agricultural uses (Figs. 2, 3, and 4). A covariance analysis using the natural 133 logarithm values of the remaining mass (In \%RM) measured for the different groups of the soil fauna 134 showed statistically significant differences for the different groups within each soil use (Tukey LSD, $135 \mathrm{p}<0.05)$. In the less disturbed system, the Naturalized Grassland (Figure 2), the decomposition rate (k) 137 calculated for the Total Biota was significantly higher and different $(\mathrm{p}<0.05)$ from the other two 138 groups, with no differences between them. In the Recent Agriculture system (Figure 3), the 139 decomposition rate $(\mathrm{k})$ of the Total Biota was significantly higher than that of the Microfauna alone, 
140 while the Microfauna + Mesofauna group did not differ with the other two groups. In the Intensive

141 Agriculture, the decomposition rate of the Microfauna was significantly lower than the other two 142 groups that did not differ from each other (Figure 4).

143 When analyzed between systems, the only significant difference found in decomposition rate 144 was for the Microfauna. Decomposition rate for this group was significantly higher in the less 145 disturbed system (NG) when compared to the two agricultural systems (Fig. 5).

146 Overall, a total of five collembola families, twenty one acari superfamilies and nine eartworm 147 species were identified in all the sampling sites altogether (data not shown).

148 4. Discussion

In this work, two of the selected agroecosystems had been each under the same use for several 150 decades, while the third system was of intermediate disturbance. It was assumed that by the time of the 151 experiment, the structure and composition of the edaphic fauna in each system was already in 152 equilibrium with the inputs and local use regime of each agroecosystem. Therefore, the results on 153 decomposition rates are proper of the fauna already adapted to each agroecosystem.

In this way, the original edaphic fauna of the region was assumed to be best represented by the 155 edaphic fauna in the NG system. In the intensive agriculture system the original fauna was subjected to decades of strong habitat changes brought about by tillage, fertilizers, pesticides, changes in temperature regime, water availability, and soil structure (Domínguez et al., 2014).

The results show that the relative contribution of each fauna group to decomposition rate is different between systems, which is an indication that the structure and composition of the edaphic fauna is different from one system to another.

In the Naturalized Grasslands, the less anthropized system, the only significant difference was found when the Macrofauna was excluded. This is an indication that it was this group the one that 163 contributed most significantly to decomposition in this system $(\mathrm{k}=0.0074)$, since no difference was 
164 found when the Mesofauna was further excluded $(\mathrm{k}=0.0032)$ (Fig. 2). In the system with intermediate

165 anthropic impact, Recent Agriculture, the only statistical difference occurred when comparing Total

166 Biota $(\mathrm{k}=0.0088)$ with Microfauna alone $(\mathrm{k}=0.001)$ (Fig. 3). This result indicates that the most

167 significant contribution to decomposition in this system is the interaction of the Macrofauna with the

168 Mesofauna together. Indeed, no difference was found when only de Macrofauna or only the Mesofauna

169 were excluded. In the Intensive Agriculture system the group that significantly contributed to the

170 decomposition was the Mesofauna because the only significant difference in this agro-ecosystem

171 occurred with its exclusion that lowers the decomposition rate (k) from 0.0086 to 0.0025. (Fig. 4).

172 When examined across systems, only the Microfauna presented significant differences between

173 agroecosystems (Figure 5). This group showed significantly higher decomposition rate in the less

174 impacted system when compared to both intermediate and high anthropic impacts. No significant

175 differences were found between systems for either Total Fauna or Mesofauna + Microfauna groups.

176 This result underscores de sensitivity of the Microfauna to anthropic activities.

177 Interestingly, and despite what other authors found for similar soils (Dominguez et al, 2014),

178 there were no significant differences due to land use intensity alone or its interaction with the edaphic

179 biota. This is consistent with Geissen et al (2009), who found that intensive management in Banana

180 fields in Mexico did not differ in litter decomposition rate when compared to successional forests on

181 the same soil.

182 In interpreting the results presented, it is important to keep in mind that the litterbag system 183 employed and the way they were deployed on the soil surface attract mainly epigeic soil fauna.

184 Therefore, most of the results are relevant mainly to this group.

185 The results obtained in this work clearly support the working hypothesis. The data show that the 186 different groups of the epigeic soil biota contribute differently to litter decomposition and that this 187 differential contribution is being mediated by the differences in soil use. Interestingly enough, these 
188 groups present complementary activities depending on soil use intensity, since no differences in 189 decomposition rates were found between uses when the decomposition rates of the entire soil biota 190 were compared. However, the contribution of each group of the soil fauna to the total litter 191 decomposition changed across soil uses.

192 Being the less disturbed system, the Naturalized Grassland is the closest to the original, pristine 193 condition of the soil systems studied. In these conditions, the Macrofauna is the relevant group as 194 reflected by the lowering of the decomposition rate brought about by its selective exclusion with no 195 further effect when the Mesofauna was also excluded. Indeed, results from previous authors (Brussaard 196 et al., 2007; Kampichler and Bruckner, 2009) indicate that in the less disturbed ecosystems, the 197 contribution of the Mesofauna to litter decomposition is only marginal respect to that of the 198 Macrofauna. Those results are in agreement with the ones presented in this work.

199 In the Recent Agriculture system, of intermediate disturbance, the combined effects of both the 200 Macrofauna and Mesofauna are relevant, since the only significant difference is the result of their 201 exclusion together.

The results from the most disturbed system, the Intensive Agriculture, show the Mesofauna as 203 the relevant group, for the only significant decrease in decomposition rate takes place when this group 204 is excluded. These results are thoroughly consistent with the hierarchical model proposed by Lavelle et 205 al. (1993). rates for the least anthropized Naturalized Grasslands when compared to both agricultural systems. No differences were found for the Total Fauna or the Macro + Mesofauna across systems. These results 209 suggests a negative effect of the agricultural practices on the Microfauna in particular. This is 210 consistent with previous research showing evidence that agricultural management affects the structure 211 of the microbial community (Wakelin et al., 2009; Zhong et al., 2010). Results by Lavelle et al. (2006). 
212 It also indicates that this particular group is very sensitive to any disturbance of the soil environment.

213 Despite their recognized importance, the interactions between the different groups of the soil

214 biota are still largely unknown and one of the most studied topics in soil ecology (Hättenschwiler et al.,

215 2005; Fitter et al., 2005; Kampichler and Bruckner, 2009; Culliney, 2013). Coûteaux et al. (1991) and

216 Bradford et al. (2002) found a significant increase in the decomposition rates when these three groups

217 (micro, meso and macrofauna) were found acting together, when compared to less complex soil fauna 218 groups.

219 It was also found that under organic agricultural management, the Mesofauna increases its 220 abundance (Kautz et at., 2006; Peredo et al., 2009) possibly due to the specialization in the 221 consumption of the sources of litter left by crops (Kautz et al., 2006; Milcu et al., 2006). The results 222 presented here also support that assumption.

In terrestrial ecosystems, the empirical evidence is scarce but it is known that when a soil 224 community has a high diversity of functional traits, it has effects that facilitate interactions promoting 225 decomposition (Gessner et al., 2010). More evidence from size-exclusion studies is needed in order to 226 thoroughly assess to what extent agricultural practices affect soil fauna diversity (Hättenschwiler et al., 227 2005; Gessner et al., 2010; Culliney, 2013) and to improve agricultural practices for soil biota 228 conservation that ensure decomposition and mineralization processes in agro-ecosystems.

The continuous disturbances in the studied agricultural systems could be selectively pressing most likely close to the one in the Naturalized Grassland system.

From the results presented here, it can also be concluded that the Microfauna is the most 234 sensitive group to anthropic disturbances, and therefore, it should be the group to be taken particularly 235 into account when devising sustainable agricultural practices. 
In conclusion, when looked at them separately the different soil uses studied in this work

238 strongly modulate the decomposition activity of each group of the soil fauna, even though the total 239 decomposition rate remains the same for all the studied systems when the whole soil biota is present.

240 These differences are likely due to changes in the structure and functioning of each one of the faunal 241 groups of the soil biota studied, brought about by the different soil use intensities.

243 decomposition of the different faunal groups as use intensity increases. In the less disturbed 244 environments, it is the Macrofauna the group contributing the most to decomposition, which is 245 consistent with the hierarchical model presented by Lavelle et al. (1993). As intensity of use increases, 246 the Mesofauna activity gains in relative importance, being the most important group in the most 247 disturbed environment.

250 Acknowledgements: The authors wish to thank Edgardo Ferrari and Pablo Peretto for allowing the use of their

252 properties as sampling sites. Loreta Gimenez provided great help with the fieldwork and laboratory

253 analyses. The comments by Dr. Esperanza Huerta and two other anonymous reviewers helped to 254 greatly improve the final draft of this manuscript. 
Bibliography.

257 Baker, G. 1998. Recognising and responding to the influences of agriculture and others land-use practices on soil fauna in Australia. Appl. Soil Ecol. 9 :303-310.

259

260

261

262

263

264

265

266

267

268

269

270

271

272

273

274

275

276

277

278

279

280

281 Ecol. 10: 263-276.

Bradford, M., Jones, T., Bardgett, R., Black, H., Boag, B., Bonkowski, M., Cook, R., Eggers, T., Gange, A., Grayston, S., McCaig, A., Kandeler, E., Newington, J., Prossesr, J., Setälä, H., Staddon, P., Tordoff, G., Tscherko, D. and Lawton, J. 2002. Impacts of soil faunal community composition on model grassland ecosystems. Science 298: 615-618.

Brussaard, L., de Ruiter, P., Brown, G. 2007. Soil biodiversity for agricultural sustainability. Agric. Ecosyst. Environ. 121: 233-244.

Coûteaux, M., Mousseau, M., Célérier, L., Bottner, P. 1991. Increased atmospheric CO2 and litter quality: decomposition of sweet chestnut leaf litter with animal food webs of different complexities. Oikos 61: 54-64.

Crossley, Jr. D., Hoglund, M. 1962. A Litter-Bag Method for the Study of Microarthropods Inhabiting Leaf Litter. Ecology 43(3): 571-573.

Culliney, T. 2013. Role of arthropods in maintaining soil fertility. Agriculture 3: 629-659.

Dechaine, J., Ruan, H., Sanchez-De León, Y., Zou, X. 2005. Correlation between earthworms and plant litter decomposition in a tropical wet forest of Puerto Rico. Pedobiologia 49: 601-607.

Domínguez, A., Bedano, J.C., Becker, A.R., Arolfo, R.V. (2014), Organic farming Fosters agroecosystem functioning in Argentinian temperate soils: Evidence from litter decomposition and soil fauna. Applied Soil Ecology, 83: 170-176.

Eisenbeis, G. 2006. Biology of soil invertebrates. In: Soil biology Vol. 6: Intestinal microorganism of soil invertebrates. Springer-Verlag, Berlin, pp. 3-53.

Faggi, A., Krellemberg, K., Castro, R., Arriaga, M., Endlicher, W. 2008. Biodiversity in the argentinean rolling pampa ecoregion: Changes caused by agriculture and urbanisation. In: Urban Ecology: An international 
perspective on the interaction between humans and nature. Springer, New York, pp. 377-389.

283 Fitter, A., Gilligan, C., Hollingworth, K., Kleczkowski, A., Twyman R., Pitchford, J. 2005. Biodiversity and ecosystem function in soil. Functional Ecology 19: 369-377.

285 Geissen, V., Peña-Peña, K., Huerta, E. (2009). Effects of different land use on soil chemical properties, 286 decomposition rate and earthworm communities in tropical Mexico. Pedobiologia, 53: 75-86.

287 Gessner, M., Swan, C., Dang, C., McKie, B., Bardgett, R., Wall, D., Hättenschwiler, S. 2010. Diversity meets decomposition. Trends in Ecology and Evolution 25 (6): 372-380.

Gonzalez, G., Seastedt, T. 2001. Soil fauna and plant litter decomposition in tropical and subalpine forests. Ecology 82:955-964.

Hättenschwiler, S., Tiunov, A., Scheu, S. 2005. Biodiversity and litter decomposition in terrestrial ecosystems. Annu. Rev. Ecol. Evol. Syst. 36: 191-218.

Kampichler, C., Bruckner, A. 2009. The role of microarthropods in terrestrial descomposition: A meta análisis of 40 years of litterbags studies. Biological Reviews 84: 375-389.

295 296

Kautz, T., Lopez-Fando, C., Ellmer, F. 2006. Abundance and biodiversity of soil microarthropods as influenced by different types of organic manure in a long-term field experiment in Central Spain. Appl. Soil Ecol. 33: $278-285$.

Lavelle, P., Blanchart, E., Martin, A., Martin, S. and Spain, A. 1993. A hierarchical model for decomposition in terrestrial ecosystems: Application to soil of the humid tropics. Biotropica 25(2): 130-150.

Lavelle, P., Spain, A. 2001. Soil Ecology. Kluwer Academic Publishers, New York, pp. 25-100.

Lavelle, P., Decaëns, T., Aubert, M., Barot, S., Blouin, M., Bureau, F., Margerie, P., Mora, P., Rossi, J. 2006. Soil invertebrates and ecosystem services. Eur. J. Soil Biol. 42: 3-15.

Li, X., Yin, X Wang, Z., Fan, W., 2014. Interaction between decomposing litter and soil fauna of the Betula ermanii forest floor of the Changbai Mountains, China. Canadian Journal of Forest Research, 2014, 44(12): 1507-1514, 10.1139/cjfr-2014-0248 
308 Liiri, M.,Häsä, M.,Haimi, j., Setälä, H., 2012. History of land- use intensity can modify the relationship between functional complexity of soil fauna and soil ecosystem services-A microcosm study. Applied Soil Ecology 55: $53-61$.

311 Lubchenko, J., Olson, A., Brubacker, L., Carpenter, S., Holland, M., Hubbell, S., Levin, S., Macmahon, J., 312 Matson, P., Melillo, J., Mooney, H., Peterson, C., Puiam, H., Real, L., Regal, P., Risser, P. 1991. The 313 sustainable biosphere initiative: an ecological research agenda. Ecology 72: 371-412.

314 Milcu, A., Partsch, S., Langel, R., Scheu, S. 2006. The response of decomposers (earthworms, springtails and 315 microorganisms) to variations in species and functional group diversity of plants. Oikos 112: 513-524.

\section{Navarrete M, D Gallopín, G Blanco, M Díaz-Zorita, M Ferraro, D Herzer, H Laterra, P Murmis, G}

Podestá, J Rabinovich, E Satorre, F Torres, E Viglizzo, (2007) Multi-causal and integrated assessment of sustainability: the case of agriculturization in the argentine pampas.

Peredo, S., Parada, E., Vega, M., Barrera, C. 2009. Edafic mesofauna community structure in organic and conventional management on cranberry (Vacciniun sp.) plantations: An agroecological approach. J. Soil Sci. Plant Nutr. 9(3): 236-244.

Ponge, JF., Pérès, G., Guernion, M., Ruiz-Camacho, N., Cortet, J., Pernin, C., Vllanave, C., Chaussod, R., Martin-Laurent, F., Bispo, A., Cluzeau, D., 2013. The impact of agricultural practices on soil biota: A regional study. Soil Biology \& Biochemistry 67: 271 - 284.

R Development Core Team, 2010. R: A language and environment for statistical computing. R Foundation for Statistical Computing, Viena,. ISBN 3-900051-07-0, URL http://www.R-project.org

331 Wakelin, S., Gregg, A., Simpson, R., Li, G., Riley, I., McKayd, A. 2009. Pasture management clearly affects soil microbial community structure and N-cycling bacteria. Pedobiologia 52: 237-251. 
333 Yang, X., Chen,J.,2009. Plant litter quality influences the contribution of soil fauna to litter

334 decomposition in humid tropical forests, southwestern China. Soil Biology \& Biochemistry 41: 910$335 \quad 918$

336 Zhong, W., Gu, T., Wang, W., Zhang, B., Lin, X., Huang, Q., Shen, A. 2010. The effects of mineral fertilizer

337 and organic manure on soil microbial community and diversity. Plant Soil 326: 511-522.

338

339 


\section{Table $\mathbf{1}$ (on next page)}

\section{ANOVA Table}

Two-way ANOVA for Mesh size, Agricultural use and the interaction. No significant interaction or effect of agricultural use, mesh size is the main significant effect found. 


\begin{tabular}{lrrrrr} 
Two-Way ANOVA & \multicolumn{1}{c}{ SS } & DF & \multicolumn{1}{c}{ MS } & \multicolumn{1}{c}{ F } & p-value \\
Intercept & $4,758.675$ & 1 & $4,758.675$ & $19,980.80$ & 0.000000 \\
Agricultural use & 0.682 & 2 & 0.341 & 1.43 & 0.240816 \\
Mesh-size & 6.427 & 2 & 3.214 & 13.49 & 0.000003 \\
Agr-use * Mesh-size & 0.685 & 4 & 0.171 & 0.72 & 0.579533 \\
Error & 62.160 & 261 & 0.238 & &
\end{tabular}


1

Sampling location

Map showing the location of the sampling sites

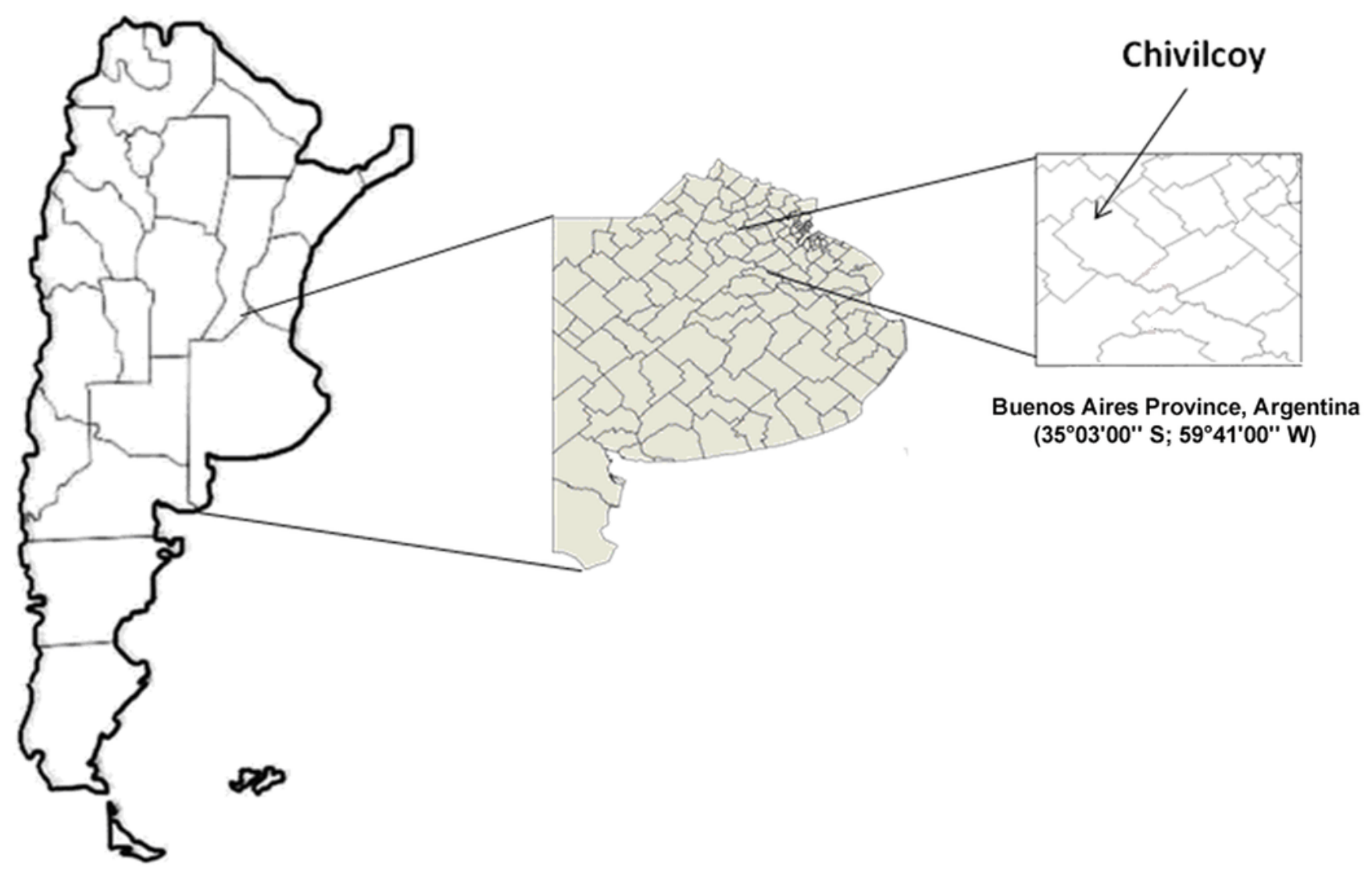


2

Remaining mass for the Naturalized grasslands system

Results for remaining mass (\%) found for the Naturalized Grassland. A significant reduction in decomposition rate occurs when the Macrofauna is excluded. Negative exponential curve and R2 values are shown for each fauna group. Decomposition rate $(k)$ corresponds to the loss of mass per day. Different letters indicate significant differences (In MR\%) through covariance analysis contrasted with Tukey HSD test $(\alpha<0,05)$. 


\section{Naturalized \\ Grassland}

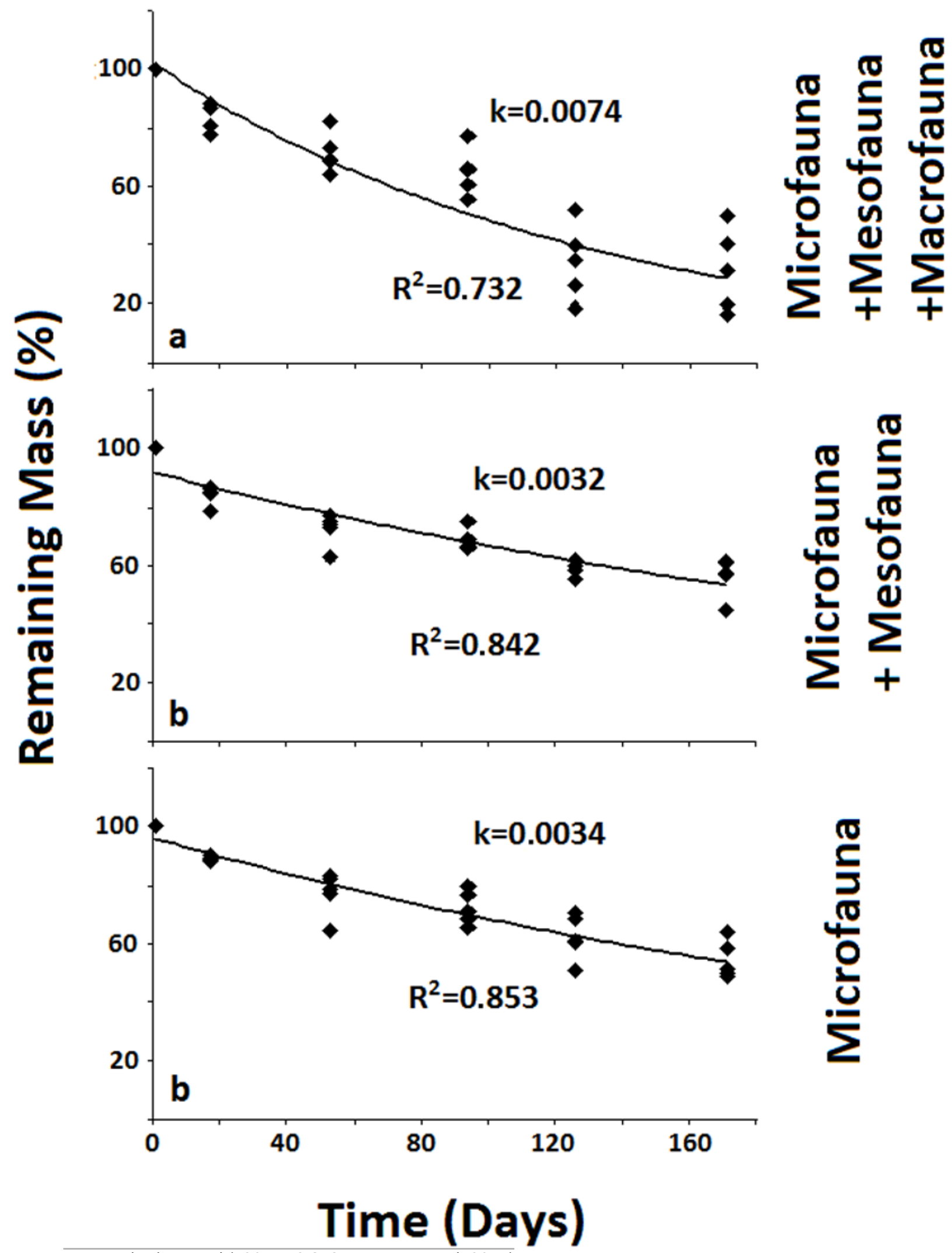


3

Remaining mass for the Recent agriculture system

Results for remaining mass (\%) found for the Recent Agriculture. Significant reduction in decomposition rate occurs when both Macro and Mesofauna are excluded together. Data shown as in figure 2 . 


\section{Recent Agriculture}

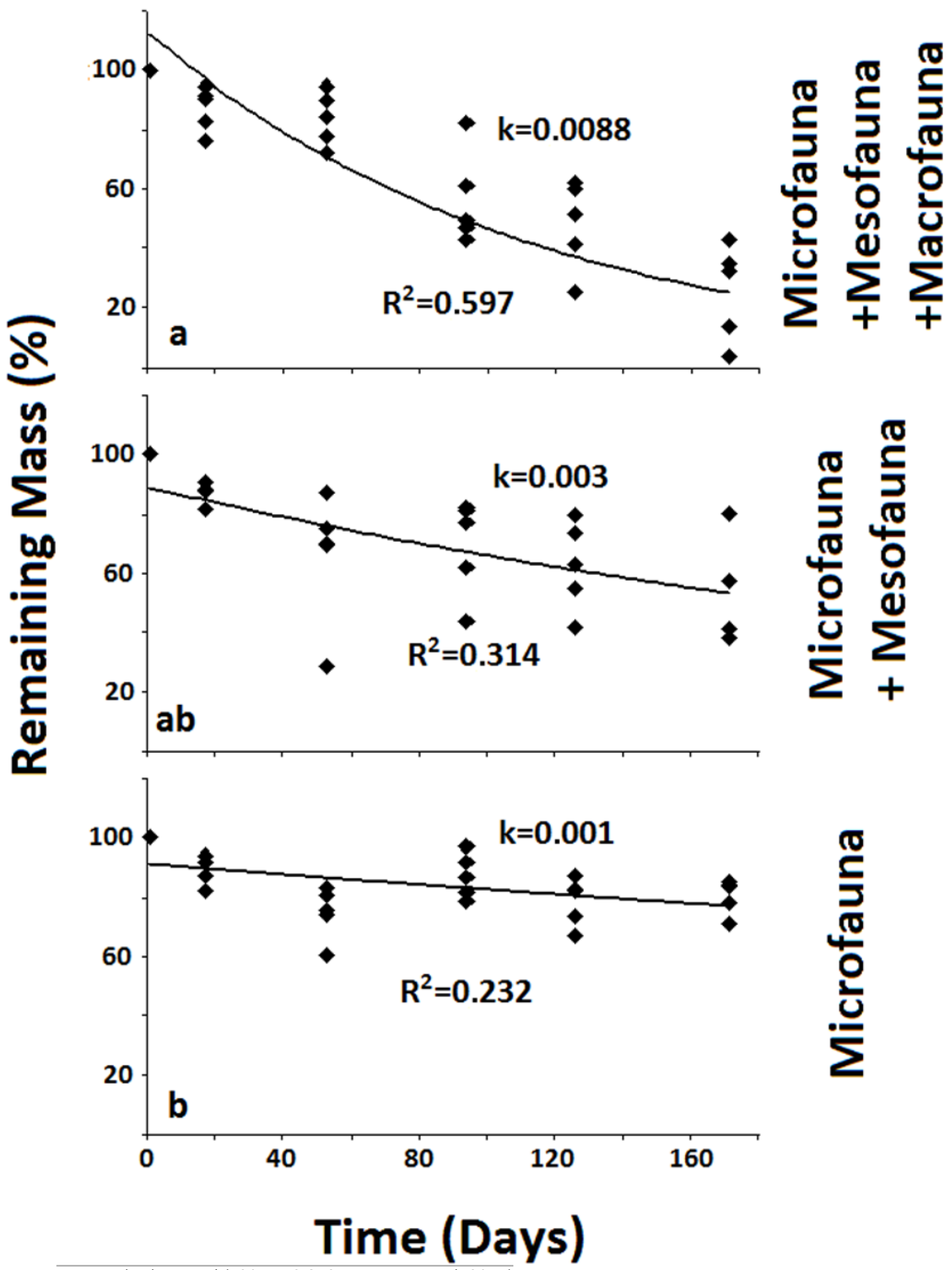


4

Remaining mass for the Intensive agriculture system.

Results for remaining mass (\%) found for the Intensive Agriculture. Significant decrease in decomposition rate occurs when the Mesofauna is excluded. Data shown as in figure 2. 


\section{Intensive \\ Agriculture}

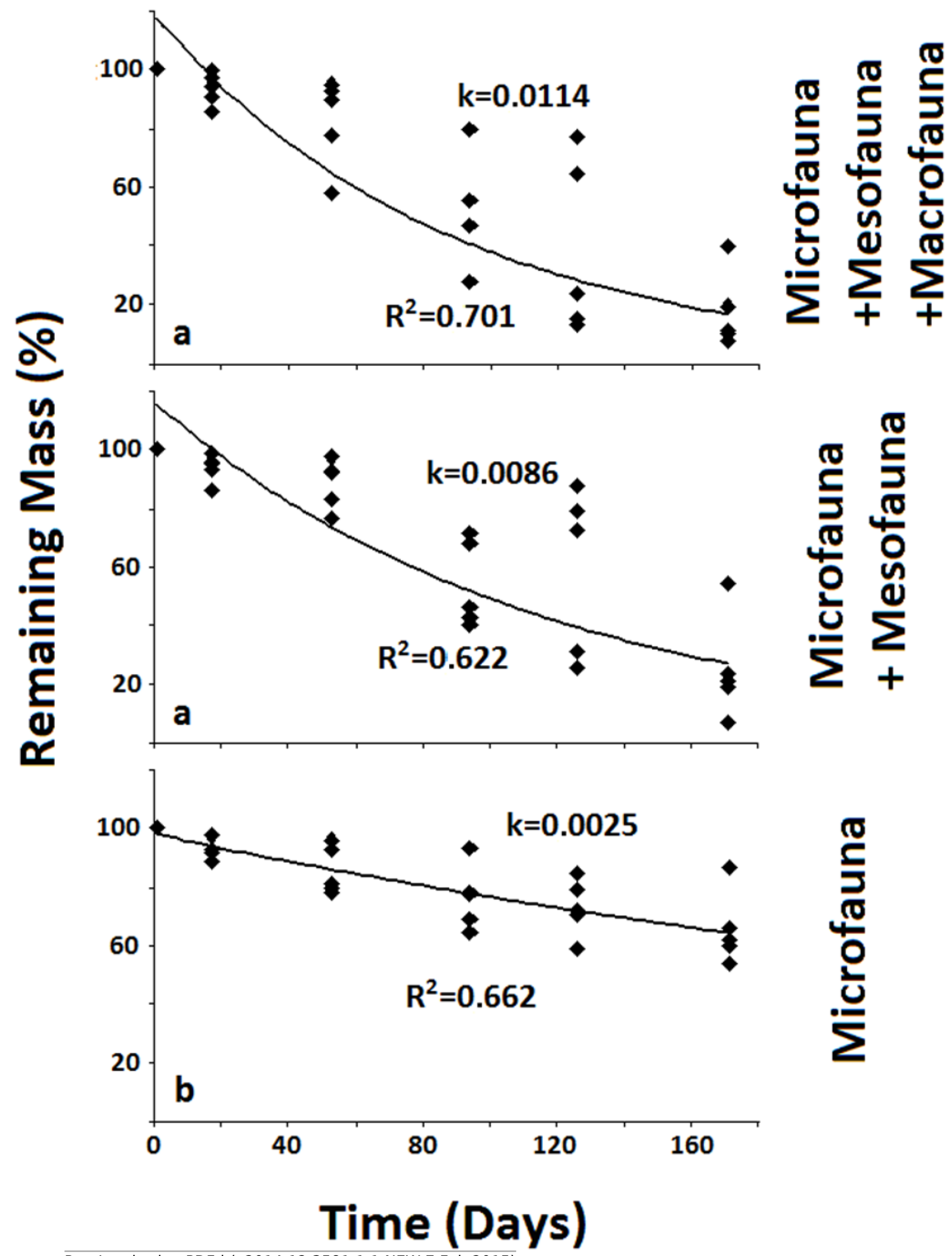




\section{5}

Remaining mass results for the Microfauna

Results for remaining mass (\%) found for the Microfauna when compared across treatments; Decomposition rate due to Microfauna activity is higher in the less anthropized system when compared to both agricultural ones. No significant differences were found for the macro or the Mesofauna across systems. Data shown as in figure 2.

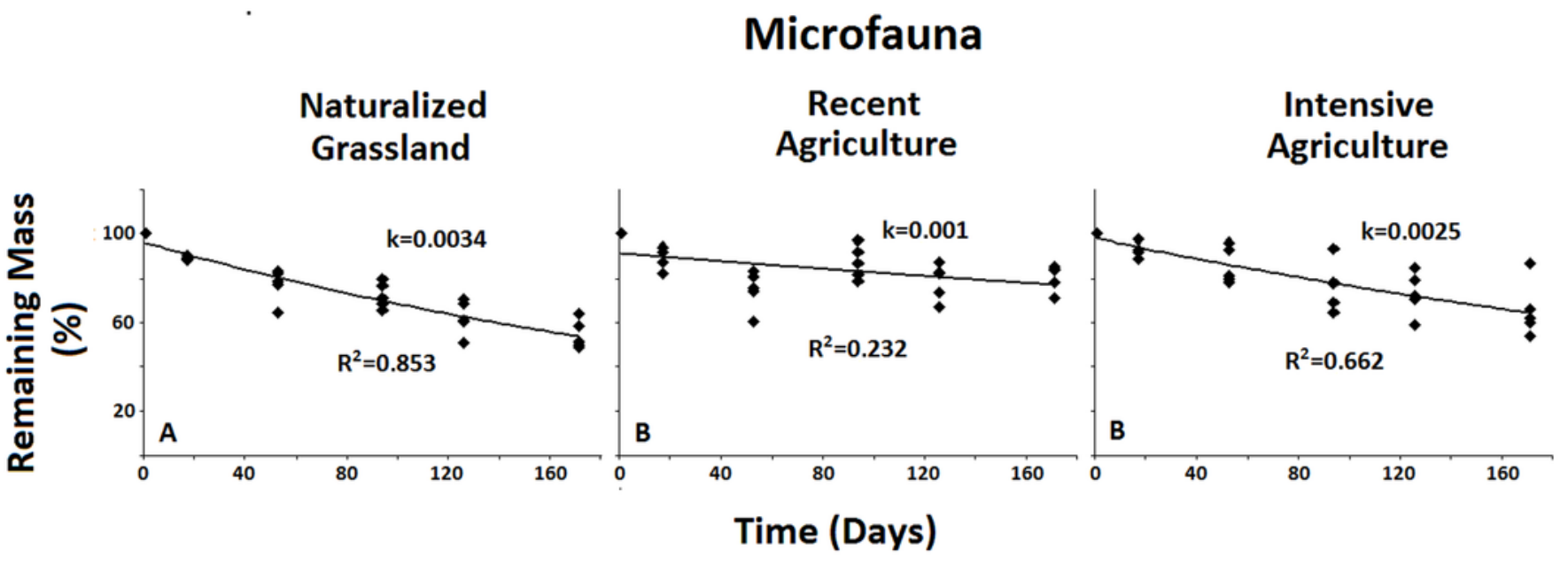

